\title{
Editorial
}

\section{Recent Improvements for Animal Health Research Reviews: Thomson Reuters Indexation, Online-Only Format and an Open-Access Option}

It is with great excitement that I have the privilege to report several recent developments for Animal Health Research Reviews. Notably, these advancements were initiated under the auspices of the previous Editor-inChief, Carlton Gyles.

Foremost is the news that Animal Health Research Reviews was recently accepted for indexation by Thomson Reuters, beginning with the June 2013 Issue. Data will be collected through 2015 before Animal Health Research Reviews receives its first impact factor in 2016. Indexation in the Thomson Reuters Web of Science, together with other databases such as MEDLINE and Scopus, is expected to significantly increase the visibility and citation of Articles published in Animal Health Research Reviews. This visibility will in turn benefit our authors, the virtual symposia that will continue to be published in Animal Health Research Reviews, and the Conference of Research Workers in Animal Diseases that is affiliated with this journal.

Next, Cambridge University Press has designed a beautiful new cover for Animal Health Research Reviews, beginning with the June 2013 Issue when the Journal switches to an online-only format. Other advantages of this new format include affordability of color figures, faster publication of accepted Articles, and more flexibility in the publication process.

The ability to submit Articles through the Cambridge University Press website is another feature that is new to Animal Health Research Reviews. This new protocol, which was first implemented after the December 2012
Issue, is expected to improve manuscript tracking as submissions increase in response to improved visibility of the Journal through the Thomson Reuters database. Some of the Articles that appear in the June 2013 Issue were submitted through this website, and eventually all Animal Health Research Reviews manuscripts will be submitted via this route.

Finally, it is my pleasure to report that the first Open Access Article for Animal Health Research Reviews will be published in the June 2013 Issue. Hopefully this will be the first of many such Articles.

In conclusion, these new developments affirm the upward trajectory of this unique and important journal. I am honored and grateful to begin my time as Editor-inChief with all of this exciting news, and it is my sincere hope that I can help maintain the excellent service provided by the outstanding Editorial Board, Section Editors, Editorial Staff of Cambridge University Press, and my predecessors as Editor-in-Chief of Animal Health Research Reviews. 